\title{
Housing Risk and Its Influence on House Price: An Expected Utility Approach
}

\author{
Yehui Wang, ${ }^{1}$ Jianxu Liu $\mathbb{D}^{1,2}$ Yuxuan Tang, ${ }^{3}$ and Songsak Sriboonchitta ${ }^{2}$ \\ ${ }^{1}$ Department of Economics, Shandong University of Finance and Economics, Shungeng Road No. 44, Jinan, Shandong, China \\ ${ }^{2}$ Center of Excellence in Econometrics, Faculty of Economics, Chiang Mai University, Chiang Mai, Thailand \\ ${ }^{3}$ International Development Cooperation Academy, Shanghai University of International Business and Economics, \\ 620 Gubei Road, Shanghai, China \\ Correspondence should be addressed to Jianxu Liu; liujianxu1984@163.com
}

Received 30 November 2019; Revised 18 February 2020; Accepted 25 February 2020; Published 28 March 2020

Academic Editor: Sergio Ortobelli

Copyright (c) 2020 Yehui Wang et al. This is an open access article distributed under the Creative Commons Attribution License, which permits unrestricted use, distribution, and reproduction in any medium, provided the original work is properly cited.

\begin{abstract}
House price is affected by households' expectation of future house price trend and volatility, where the expected volatility of housing capital return, indicated by variance, is defined as the housing market risk. Theoretically, risk element cannot be directly inserted in the standard housing models because most of the models are built on the underlying assumption of certainty. Extending the life-cycle model to a two-asset expected utility case with uncertainty, we show house price is affected by housing market risk premium, which is a function of households' risk-aversion coefficient, real housing wealth, and expected housing volatility. Empirical analysis relying on China's 2001-2018 provincial housing panel data supports the theoretical innovation. Despite the empirical results show that the effect of housing market risk on house price is tiny, simulations suggest that the consideration of risk is quite helpful in analyzing and predicting the long-run house price equilibriums.
\end{abstract}

\section{Introduction}

Over the past 20 years since entering the 21st century, house prices are sharply raised in most of the developing and developed countries. This worldwide event gives people an impression that investment in housing market is relatively better on asset preservation and appreciation. However, house price does not increase always. For instance, Japan experienced housing market collapse in 1991, where the price in 2003 is only $1 / 4$ of the price in 1990; as the indicator of Southeast Asia, Hong Kong's house price reduced from 13000 to 5000 (HK dollar) during the Southeast Asia Financial Crisis; and in the recent 2007-2008 Global Financial Crisis, house prices in lots of countries are dramatically reduced. Housing market risk gradually comes into our view. Academically, many attentions focus on house price prediction; however, although classical housing economic models work very well in common periods, they always get lost in the depreciations.

The development on house price theories has a long history such as (i) the "mark-up" model ([1]) where house price is mainly tracked by construction cost, especially the land price, (ii) the reduced-form models ([2]) where demand and supply of housing services are described, (iii) the housing stock-flow model $([3,4])$ where the housing stock is accumulated by the flow of housing purchases, (iv) the hedonic model ([5]) where house price is determined by lots of factors, and (v) the housing life-cycle model ([6]) where house is clearly defined as both consumption and investment products. Despite the standard housing life-cycle model is popularly used in analyzing housing issue, there is no position for risk element in the theoretical framework. Lots of research studies concentrate on this issue, but they find that the fundamental problem is that the standard model is built on the underlying assumption of certainty. The assumption of certainty implies that house price has no risk (unexpected future volatility); thus, people are perfectly informed even for future prices. As the series of studies (e.g., $[3,4,7-10]$ ) suggested, the assumption of rational expectations should be rejected. They also claim that, under the assumption of certainty, the house price derivation of the standard model 
actually reflects the price of "nonrisk" houses. However, the price of realistic houses is risky. So, even the early studies, such as Poterba [3], recognised the importance of a risk premium in an asset pricing framework.

The issue of risk is deeply studied in financial area. Financial theory originated with the mean-variance portfolio model [11] and evolved into the capital asset pricing model (CAPM) [12-14]. The CAPM shows that the return of any risky asset is equal to a riskless rate plus a risk premium for a particular risky asset. However, the empirical support for the static CAPM was weak $[15,16]$, which may reflect theoretical failings arising from many simplifying assumptions as well as difficulties in implementing valid tests of the model [17]. Consequently, the consumption-based capital asset pricing model (C-CAPM) was developed by Lucas [18] as a dynamic generalization of the CAPM also linking it to the real macroeconomy. In contrast to the CAPM, it can theoretically show how economic fundamentals affect returns and prices of risky assets. Nevertheless, housing was not incorporated in asset allocation models of the C-CAPM type until Grossman and Laroque [19]. Furthermore, Flavin and Nakagava [20] found that their housing model, which adds nondurable consumption in the utility function to extend Grossman and Laroque [19] beyond durable housing being the sole argument in utility, provides support for the C-CAPM. Piazzesi et al. [21] proposed a nonseparable utility model aggregating "shelter" and "consumption" via a constant elasticity of substitution index and found that the change in the expenditure share emerges as a second factor, complementing the single-factor C-CAPM, in their "housing C-CAPM" [21]. In an empirical context, Case et al. [22] developed a multifactor housing asset pricing model and found that house prices are determined not only by riskless assets and a theoretically derived risk premium but also by idiosyncratic risk, momentum, and a size effect, where Banz [23] suggested that returns on small firms were relatively high. Therefore, given on all the above studies, expected future volatility of housing capital return is commonly defined as housing (market) risk and empirically measured by variance of the housing capital return; however, their theoretical definitions of the risk premium are slightly different, but most of them estimate risk premium empirically based on standard C-CAPM definitions [24]. In addition, some studies track the determinants of housing market risk premium such as the uncertainties in interest rate, inflation, and income and then research on a specific aspect and define the decomposed risk (premium) separately such as the interest risk of housing, inflation risk of housing, and households' income risk of housing $[25,26]$. However, these separately defined risks or risk premiums are not the interest in this paper.

The theoretical framework about the continuous-type life-cycle model under uncertainty can be tracked back to Merton's "lifetime portfolio selection under uncertainty: the continuous-time case" [27]. This framework can estimate the time-varying risks but is not typically for housing issues. Rely on this framework, some further studies (e.g., [28-31]) measure and explore housing risks. However, most of these do not take to much experience from housing models, especially Dougherty and Van Order's housing life-cycle model. It means that they still treat house as a pure financial asset and ignore its consumption property (demand). However, even if houses cannot be traded, the uncertain future prices will also affect households' consumption demand of housing services. Recently, although the most relevant study [32] derives the results based on the discrete type of households' lifetime utility and discrete type of lifetime budget constraints, whether the continuous-type modelling has effect or not still needs to be checked. In addition, massive of studies focus on the portfolio decision between housing and financial assets, or the interaction between housing and financial markets [33], which are not the interest in this paper.

Based on the above and some other relevant studies, a couple of points can be summarized: (1) according to the comparison between the CAPM and C-CAPM, housing market risk should be automatically derived from the model rather than subjectively defined. (2) The necessary condition of getting a risk element in the theoretical derivation is the allowance and the consideration of uncertainty. (3) Pure financial models especially the CAPM-type models are not appropriate in describing and analyzing house issues because houses not only have investment property/demand but also have consumption property/demand. In light of these, it is necessary to rebuild the standard housing lifecycle model, where housing purchase is risky and households' lifetime utility is uncertain, and then to test whether a theoretically coherent measure of the risk premium can be derived, parallel to that used in financial economics.

Therefore, this paper is organized as follows. Section 2 is the theoretical section including the mathematical background of the standard housing life-cycle model, the results when the standard model and CAPM are combined, and the expected utility housing life-cycle model. Section 3 is the empirical section in which the effect of housing market risk will be analyzed based on China's housing data. Simulations will be given and discussed in Section 4. Conclusions are drawn in Section 5. References and appendixes are given at the end.

\section{Theory}

In this section, the standard housing life-cycle model will be firstly introduced. Based on its assumptions, we will then discuss why the standard user cost equation is biased in estimating house price. Given by the standard user cost equation, the more specific house price equation can be derived through a simple link between the certain and uncertain housing capital returns corresponding with the theory of uncertainty. Although this combined complement method is simple, the consistency between models is hard to be proved. After that, a fully developed and consistent theoretical model, the two-asset expected utility housing lifecycle model, is shown. The general and special derivations of house price as well as the use cost of capital (UCC) will also be shown and discussed. 
2.1. Standard Housing Life-Cycle Model. The standard intertemporal housing life-cycle model extended to housing assumes two goods, housing services and a composite consumption good (C). The model has a long history, including as noted above [6]. If, for simplicity, the flow of housing services is proportional to the demand for the housing stock $(\mathrm{H})$, and given an assumed constant real discount rate (r), lifetime utility is described in an infinite horizon continuous time by the following equation:

$$
\int_{0}^{\infty} e^{-r t} \mu[H(t), C(t)] \mathrm{d} t
$$

$\mu[H, C]$ denotes the instantaneous utility of the representative household. (1) is maximized with respect to the budget constraint (2) and technical constraints (3) and (4), which describe changes to real asset stocks (housing and financial, respectively) over time. In addition, for the purpose of simplicity, the issues of tax and housing transaction cost are removed [3].

$$
\begin{aligned}
g(t) X(t)+S(t)+C(t) & =\mathrm{RY}(t)+i(t) A(t), \\
\dot{H}(t) & =X(t)-\delta(t) H(t), \\
\dot{A}(t) & =S(t)-\pi(t) A(t),
\end{aligned}
$$

where $H(t)=$ stock demand for housing, $g(t)=$ real purchase price of dwellings, $X(t)=$ new purchases of dwellings, $S(t)=$ real savings net of real new loans, $\mathrm{RY}(t)=$ real household income, $i(t)=$ market interest rate, $A(t)=$ real net nonhousing assets, $\delta(t)=$ depreciation rate on housing, $\pi(t)=$ general inflation rate, and $\dot{\mathrm{x}} \equiv \mathrm{d} x(t) / \mathrm{d} t$ denotes the time derivative for any variable $x(t)$.

From the first-order conditions (see Appendix A), the marginal rate of substitution (MRS) between housing and the consumption good, $\mu_{H} / \mu_{C}$, is given by (5), where $r_{H}(t)=[\mathrm{d} g(t) / \mathrm{d} t] / g(t)$ is the real price growth rate:

$$
\begin{aligned}
\left(\mu_{H}(t) / \mu_{C}(t)\right) & =g(t) \cdot U C C(t) \\
& =g(t) \cdot\left[i(t)-\pi(t)+\delta(t)-r_{H}(t)\right] .
\end{aligned}
$$

The term in [...] in the right-hand side is the widely-used standard definition of the real housing user cost of capital (UCC). The left-hand side is the marginal rate of substitution between housing and consumption good, and this MRS should equal the imputed rental price of housing services $(R)$ which means that households' utility is unchanged if their housing services cut down unit, but they obtain some nonhousing goods as compensations. Thus, (5) can be rewritten as $R(t)=g(t) \cdots U C C(t)$, and this is the well-known arbitrage condition. Equation (5) can also be written as follows:

$$
\left(\frac{R(t)}{g(t)}\right)+r_{H}(t)-\delta(t)=i(t)-\pi(t) .
$$

The left-hand side of (6) is the real net housing return, which is the sum of housing rental yield $(R / g)$ and housing capital return $\left(r_{H}\right)$ minus the housing depreciation rate, and the right-hand side is the real interest rate on liquid assets, or the risk-free rate. Given the assumption of certainty, the future house price is observable, so the housing capital return is certain. Equation (6) implies that there is no difference in the final returns whether people choose buy-to-let investment or bank saving. As we know, housing investment should be risky because its capital return is practically uncertain. So, the problem is that housing in the standard model is assumed to be risk-free. The derived house price equation (not shown) actually refers to the price of the "riskfree housing asset" rather than the price of the practical risky houses.

2.2. Combined Complement Method. Now, we assume that there are two kinds of housing assets in the market: one is risky and another is risk-free. Risk-free houses can be simply regarded as the houses play on option market where owners know the future prices of their houses. The real capital return of the risk-free houses is certain and marked as $r_{H \text {,free, }}$ and the real capital return of the risky houses is uncertain and marked as $r_{H \text {,risky. }}$.

In order to guarantee two kinds of houses have no absolute advantage compared with another one in the market, the expected utilities of the final wealth of the two kinds of houses should be indifferent, given by (7), where $H W$ is the real housing wealth (or real housing value):

$$
\mu\left[\left(1+r_{H, \text { free }}\right) H W\right]=E\left\{\mu\left[\left(1+r_{H, \text { risky }}\right) H W\right]\right\} .
$$

The utility function, $\mu[\ldots]$, is concave, and the general result implies that $E\left[r_{H \text {,risky }}\right]>r_{H \text {,free. }}$ In order to solve the issue and calculate a more specific result, two more conditions are needed: the distribution function of the uncertain element $\left(r_{H \text {,risky }}\right)$ and a specific utility function. The real capital return is assumed to be distributed normally as (8), and the CARA (constant absolute risk aversion) utility function (9) is selected to be the specific utility function, in which $\gamma$ is the Pratt(1964)-Arrow(1971) parameter of CARA $[21,34]$ :

$$
\begin{aligned}
r_{H, \text { risky }} & \sim N\left[r_{H, \text { risky }}^{e}, \sigma_{H, \text { risky }}^{2}\right], \\
\mu[x] & =-\exp [-\gamma x] .
\end{aligned}
$$

The derivation of equation (10) is shown in Appendix B, and the capital return from the risk-free house (if such a thing existed) should be the same as the expected capital return on the risky house minus a housing risk premium. The housing risk premium is determined by the CARA parameter, real housing wealth, and the expected housing volatility. Substituting (10) into (5), the cost of capital for risky houses is described by (11):

$$
\begin{gathered}
r_{H, \text { free }}=r_{H, \text { risky }}^{e}-0.5 \gamma \cdot H W \sigma_{H, \text { risky }}^{2} \\
R(t)=g(t) \cdot\left[i(t)-\pi(t)+\delta(t)-r_{H, \text { risky }}^{e}+0.5 \gamma \cdot H W \sigma_{H, \text { risky }}^{2}\right] .
\end{gathered}
$$

Although oversimplified, (11) provides the first insights and shows that it is not sufficient just to include a measure of 
the price variance in empirical studies because risk also depends on other factors, notably the market value of the housing stock. Despite the combined complement method is simple and easily understandable, it is very difficult to illustrate the consistency between the standard housing lifecycle model and the theory of uncertainty.

2.3. Expected Utility Housing Life-Cycle Model. In this section, housing acts as both a consumption good and a risky asset. Liquidity of a risky asset including housing will affect the asset price [35], but for the purpose of simplicity, we have already removed the costs of housing in the theoretical framework in Section 2.1, and therefore, housing now is a liquid risky asset. The liquidity issue will be studied in our further work. In contrast to the standard model, the extension is to treat housing as risky in terms of the capital return. Extending the standard life-cycle housing model to the uncertain case, compared to equation (1), households maximize their expected lifetime utility (12). Although the constraints mathematically are still (2)-(4), some related mathematical derivations are different. Typically, future house price $(g(t+\mathrm{d} t))$ as well as expectation on housing capital return $\left(r_{H, \text { risky }}(t)\right)$ in time period $(t)$ for the following period $(t+\mathrm{d} t)$ is uncertain now (see Appendix C).

$$
U=E\left\{\int_{0}^{\infty} e^{-r t} \mu[H(t), C(t)] \mathrm{d} t\right\}
$$

From the first-order conditions (see Appendix C), the MRS between housing and the consumption good $\left(E\left[\mu_{H}\right] / E\right.$ $\left.\left[\mu_{C}\right]\right)$ is given by

$$
\begin{aligned}
\left(\frac{E\left[\mu_{H}(t)\right]}{E\left[\mu_{C}(t)\right]}\right)= & g(t) \cdot \mathrm{UCC}_{\text {risky }}(t)=g(t) \\
& \cdot\left[i(t)-\pi(t)+\delta(t)-\frac{E\left[r_{H, \text { risky }}(t) \mu_{C}(t)\right]}{E\left[\mu_{C}(t)\right]}\right],
\end{aligned}
$$

where $E\left[\mu_{H}(t)\right]=\partial E[\mu[H(t), \quad C(t)]] / \partial H(t)$, the expected marginal utility of housing, and $E\left[\mu_{C}(t)\right]=\partial E[\mu[H(t), C(t)]] /$ $\partial C(t)$, the expected marginal utility of consumption.

Equation (13) shows a generalized MRS and UCC under uncertainty. When housing capital return is certain, expected marginal utility of consumption in both numerator and denominator will be canceled, and then the right-hand side of (13) would reduce to the widely-used standard definition (5). UCC can be rewritten as (14) and (15), where the newly derived term in UCC is $\tau$. $\tau$ is quite the same as the risk premium derivation in the C-CAPM, but equation (15) is specifically for housing. Similar to the risk premium derivation in the C-CAPM, $\tau$ is the finally generalized theoretical form of the housing market risk premium. Equation (14) points out that user cost of capital is negatively affected by expected housing capital return but positively affected by the housing market risk premium:

$$
\begin{aligned}
\operatorname{UCC}(t) & =i(t)-\pi(t)+\delta(t)-r_{H, \text { risky }}^{e}(t)+\tau(t), \\
\tau(t) & =-\operatorname{Cov} \frac{\left[r_{H, \text { risky }}(t), \mu_{C}(t)\right]}{E\left[\mu_{C}(t)\right]} .
\end{aligned}
$$

In some financial literatures, consumption data are used to check whether risk premium derivation is significant or not. In contrast, consumption is endogenous in our expected utility model. This makes the risk premium derivation much abstract. To be able to derive intuitive results of the housing market risk premium $(\tau)$, specific utility function and distribution of housing capital return are needed. Practically, we should identify the specific households' utility and the distribution of the expected housing capital return of a specific housing market and then calculate the specific form of $\tau$. However, evidences from previous studies show that the different distribution functions and the utility functions will cause different special solutions. More specifically, both the kurtosis (heavy-tail issue) and skewness (asymmetric issue) have impacts on the risk premium derivation and the distribution of housing capital return compared with normal is practically heavy-tailed and asymmetric [36, 37]. Furthermore, different utility functions have different risk-averse coefficients and different curvatures, which influence the effect of risk on price [38]. For different housing markets, the distribution of households' expectation of housing capital return and utility function are unique. In order to capture the main line and avoid the complicated works, here, for simplicity, the distribution is assumed to be normal. Similarly, the standard CARA and CRRA (constant relative risk aversion) utilities are employed [38] which are given by equations (16) and (17). The main aim is to understand the calculation process in this paper. The effects of the specific distributions and utilities will be studied in the future.

Case I. Housing capital return is distributed normal as equation (8) and utility function is CARA utility denoted by equation (16).

Case II. Housing capital return is distributed normal as equation (8) and utility function is CRRA utility denoted by equation (17).

$$
\begin{aligned}
& \mu[H(t), C(t)]=-\exp [-\phi H(t)]-\exp [-\phi C(t)], \\
& \mu[H(t), C(t)]=\frac{H(t)^{(1-\theta)}}{1-\theta}+\frac{C(t)^{(1-\theta)}}{1-\theta} .
\end{aligned}
$$

The specific analytical effect of the housing market risk $(\tau)$ under CARA and CRRA utilities are derived in Appendixes $\mathrm{D}$ and $\mathrm{E}$, respectively, given by equations (18) and (19). Equation (18) is completely the same as (11) because of the different scales of the risk aversion (e.g., $\gamma=2 \phi$ ). By definitions, $\phi$ is the CARA coefficient and $\theta / C$ is the CRRA coefficient. In finance, the variance of the expected asset return is usually defined as (total) risk. Similarly, the variance term in (18) and (19) is housing market risk. In light of this, the housing market risk premium is a function of the specific risk-averse coefficient, real house price, housing 
stock, and housing market risk. The existence of real housing wealth is unsurprised as some microstudies found that the effect of housing risk varies over different income groups [39]. The construction of $\tau$ is also supported by the empirical founding provided by Case et al. [22]. Equation (19) is analogous to the ratio of the real relative quantities of housing services and the consumption numeraire derived by Piazzesi et al. [21] under their nonseparable CRRA utility:

$$
\begin{aligned}
\tau_{\mathrm{CARA}}(t) & =\phi \cdot g(t) H(t) \sigma_{H, \text { risky }}^{2}(t), \\
\tau_{\mathrm{CRRA}}(t) & \approx \frac{\theta C^{e}(t)^{-\theta-1}}{E\left[\mu_{C}(t)\right]} \cdot g(t) H(t) \sigma_{H, \text { risky }}^{2}(t) \\
& \approx \frac{\theta}{C(t)} \cdot g(t) H(t) \sigma_{H, \text { risky }}^{2}(t) .
\end{aligned}
$$

Compared with other studies, our housing market risk premium $(\tau)$ has more than two elements including housing market risk. In other words, it cannot simply add a variance term in regression as before because the coefficient should be variable-varying with households' risk-averse attitude and real volume of housing wealth. More details will be discussed in the empirical section.

The user cost of capital is positively affected by $\tau$ and thus positively affected by the level of households' risk-averse, the real housing wealth, and the housing market risk. Because real house price is negatively affected by UCC, the effects of these four elements particularly house price itself on house price are negative. House price has an in-built negative feedback adjustment through housing market risk premium. When housing market is overheated, even given by the same housing market risk, house price works as an amplifier to extend the housing market risk premium and then to cool down itself through a housing collapse. As risk is always positive but return is not, this very special in-built mechanism can help to explain (i) why house price steady grows in the boom but sharply falls in the bust and (ii) why standard housing models work very well in common periods but are terribly biased in forecasting long-run house price level.

\section{Empirical Section}

In this section, the main purpose is to check whether housing risk term is significant or not, and if it is significant, then estimate its marginal effect on house price. Technically, China's housing market is selected to be the research object for three reasons: (i) China's statistic office provides both monthly and annual house price indexes. The volatility (annual variance) of the later could be captured from the former. (ii) Provincial data is available and therefore the relation can be analyzed by panel data method, which is relatively robustness than the single-equation time-series analysis. (iii) China's house price index is the price per unit square meter which will then be less likely affected by the housing market regional heterogeneity compared to the indexes which measure the price per house.
3.1. Data and Tests. The final data set is a panel including 31 China's provinces except Taiwan, Hong Kong, and Macao during 18 years from 2001 to 2018. 13 variables are contained in this annual data set, and their details are listed in Table 1. Except interest rate, all variables are obtained from China Statistical Yearbook; interest rate is proxied by the base interest rate on RMB loans which is provided by China Financial Statistical Yearbook. Despite the means of the annual house price index (HP) and the estimated annual house price index $(\mathrm{HPm})$ are not completely the same, their correlation is 0.9992 . So, the estimated housing volatility has the ability to capture the annual fluctuation. As shown in Table 1, logarithms of the real house price and real disposable income are formed which will be applied in the empirical analysis. In addition, because the CRRA parameter $(\theta)$ is unknown and the empirical effect of term $(\tau)$ is in the same position, we assume that $\theta=1$.

Stationary test is necessary in deciding which kind of panel models will be selected in this specific analysis. Four variables are mainly focused; they are real house price (lg), real income (lry), interest rate ( $i)$, and housing market risk (tau). Because of the panel data set, the stationarity of these four variables are checked by LLC, IPS, ADF-Fisher, and Hadri LM stationary tests, shown in Table 2. Because LLC and Hadri LM tests require a balanced panel, Tibet is removed in tau. Notice that the null hypotheses of the former three tests are that the variable is unit-root, but the null of the last one is that the variable is stationary. After comprehensive consideration, results support that real house price (lg) and real income (lry) series contain unit-roots in all panels, but interest rate $(i)$ and housing risk (tau) are stationary in all panels.

3.2. Empirical Analysis. Because (1) the imposed housing rent $(R)$ is unavailable and (2) the logarithm of user cost of capital (UCC) cannot be simply decomposed in a linear form of its components, the theoretical equation and the empirical equation are slightly different. Lots of studies (e.g., [1]) describe how to derive a simple empirical equation (21) based on theoretical formula (20) which is the logarithm form of (5). Given on our slightly different UCC derivation (14), the housing risk term (tau) could be added into the formula in a similar pattern as interest rate and housing capital return, shown by equation (22). In general, a vector $\boldsymbol{X}$ is used to show the explanatory variables of imposed housing rent. As the data are available, personal disposable income (lry) is selected to capture the change in $\ln (R)$. In addition, keep in line with previous studies (e.g., [1]), households' expectation on future housing capital returns $\left(r_{H}\right.$ in the standard model and $r_{H \text {,risky }}^{e}$ in the expected utility model) and inflation rate $(\pi)$ are jointly approximated by last nominal house price growth rate $\left(r_{H, \text { risky }}^{e}(t)+\pi(t)=\right.$ $r h(t-1))$. 
TABle 1: Data description.

\begin{tabular}{|c|c|c|c|c|}
\hline Variable & Name & Label/measurement & Mean & Std.dev. \\
\hline HPM & Monthly house price & Yuan $/ \mathrm{m}^{2}$ & & \\
\hline rhm & Price growth rate & $r h m_{t}=\ln \left(\mathrm{HP} M_{t}\right)-\ln \left(\mathrm{HP}_{t-1}\right)$ & & \\
\hline meanHPM & Annualized house price & Annualized mean of monthly price & 5009.6 & 4052.3 \\
\hline varh & Housing volatility & Annualized variance of monthly $r h m_{t}$ & 0.084 & 0.385 \\
\hline HS & Housing space sold & Annual, 10 thousand $\mathrm{m}^{2}$ & 2862.4 & 2765.5 \\
\hline $\mathrm{HE}$ & Housing expenditure & Annual, 100 million yuan & 1592.1 & 2194.1 \\
\hline $\mathrm{HP}$ & House price & $\mathrm{HP}=\mathrm{HE} / \mathrm{HS}$, yuan $/ \mathrm{m}^{2}$ & 4566.0 & 3730.9 \\
\hline $\mathrm{rh}$ & Price growth rate & $r h_{t}=\ln \left(\mathrm{HP}_{t}\right)-\ln \left(\mathrm{HP}_{t-1}\right)$ & 0.102 & 0.099 \\
\hline CPI & Consumer price index & $2000=100$ & 123.1 & 17.72 \\
\hline G & Real house price & $G=\mathrm{HP} / \mathrm{CPI}$ & 35.953 & 27.701 \\
\hline $\lg$ & Logarithm form & $\lg =\ln (G)$ & & \\
\hline $\mathrm{Y}$ & Disposable income & Urban citizens, yuan/person & 18218.8 & 10332.2 \\
\hline $\mathrm{RY}$ & Real income & $\mathrm{RY}=Y / \mathrm{CPI}$ & 142.028 & 68.680 \\
\hline lry & Logarithm form & $\operatorname{lr} y=\ln (\mathrm{RY})$ & & \\
\hline ry & Real income growth & $r y_{t}=\ln \left(\mathrm{RY}_{t}\right)-\ln \left(\mathrm{RY}_{t-1}\right)$ & 0.0775 & 0.0286 \\
\hline $\mathrm{C}$ & Final consumption & 100 million yuan & 6136.5 & 6342.3 \\
\hline $\mathrm{i}$ & Interest rate & Base rate, on loans & 0.0525 & 0.0056 \\
\hline inf & Inflation rate & $\inf _{t}=\ln \left(\mathrm{CPI}_{t}\right)-\ln \left(\mathrm{CPI}_{t-1}\right)$ & 0.0248 & 0.0197 \\
\hline tau & Housing market risk & $\mathrm{tau}=0.5 \times \mathrm{HE} / \mathrm{C} \times$ varh & 0.0041 & 0.0114 \\
\hline
\end{tabular}

TABle 2: Panel data unit-root/stationary test ( $p$ value).

\begin{tabular}{lcccc}
\hline Test & lg & lry & i & tau \\
\hline Levin-Lin-Chu (LLC) test & $<0.001$ & $<0.001$ & $<0.001$ & $<0.001$ \\
Im-Pesaran-Shin (IPS) test & 1.000 & 0.415 & 0.034 & $<0.001$ \\
$\begin{array}{l}\text { ADF-Fisher unit-root test } \\
\text { (lag=2) }\end{array}$ & 0.985 & 0.179 & 1.000 & 0.008 \\
Hadri LM stationary test & $<0.001$ & $<0.001$ & $<0.001$ & 0.898 \\
\hline
\end{tabular}

$\ln (G)=\ln (R)-\ln (U C C)=\ln (R)-\ln \left(i-\pi+\delta-r_{H}\right)$,

$$
\lg (t)=a_{0}+a_{1} \cdot X(t)+a_{2} \cdot i(t)+a_{3} \cdot r h(t-1)+\varepsilon(t),
$$

$$
\lg (t)=a_{0}+a_{1} \cdot X(t)+a_{2} \cdot i(t)+a_{3} \cdot r h(t-1)+a_{4} \cdot \operatorname{tau}(t)+\varepsilon(t)
$$

Because variables are nonstationary, equation (22) should be analyzed by error correction-type models. Because our data set is a panel, there are three possible cointegration relations, given by (23)-(25). Equation (23) implies that the short-run and long-run relations are the same in all regions; equation (24) implies that the short-run relations and errorcorrection speed vary across regions, but they will converge in the same long-run relation; equation (25) implies that, for all regions, each has its own error-correction approach. In addition, individual effect $\left(u_{i}\right)$ should also be considered in this panel data analysis.

$$
\begin{aligned}
& \Delta \lg _{i, t}=\beta \Delta \operatorname{lry}_{i, t}+\eta\left[\lg _{i, t-1}-a_{1} \operatorname{lry}_{i, t-1}-a_{2} i_{i, t-1}-a_{3} r h_{i, t-2}-a_{4} \operatorname{tau}_{i, t-1}\right]+u_{i}+\varepsilon_{i, t}, \\
& \Delta \lg _{i, t}=\beta_{i} \Delta \operatorname{lry}_{i, t}+\eta_{i}\left[\lg _{i, t-1}-a_{1} \operatorname{lry}_{i, t-1}-a_{2} i_{i, t-1}-a_{3} r h_{i, t-2}-a_{4} \operatorname{tau}_{i, t-1}\right]+u_{i}+\varepsilon_{i, t}, \\
& \Delta \lg _{i, t}=\beta_{i} \Delta \operatorname{lry}_{i, t}+\eta_{i}\left[\lg _{i, t-1}-a_{i 1} \operatorname{lry}_{i, t-1}-a_{i 2} i_{i, t-1}-a_{i 3} r h_{i, t-2}-a_{i 4} \operatorname{tau}_{i, t-1}\right]+u_{i}+\varepsilon_{i, t} .
\end{aligned}
$$

The nonstationary heterogeneous panel model could estimate (23)-(25) because it has three analogical specifications: pooled mean-group (PMG) regression, mean-group (MG) regression, and dynamic fixed-effect (DFE) regression. The only difference is that the former two regressions estimate the average coefficient rather than specific coefficients for all regions. Notice that the average is enough for our analysis and the specific regional patterns are not our interest. Regression results are shown in Table 3.

The cointegration patterns are posterior determined by the Hausman test. Based on the tests among MG\&PMG $\left(\right.$ Prob $\left.>\mathrm{chi}^{2}=0.15\right), \quad$ MG\&DFE $\quad\left(\right.$ Prob $\left.>\mathrm{chi}^{2}=1.00\right)$, and PMG\&DFE (Prob $\left.>\mathrm{chi}^{2}=1.00\right)$, the dynamic fixed-effect
(DFE) estimator is inconsistent compared with the other two estimators, so it is relatively more efficient. The results of the Hausman tests suggest that the spatial heterogeneity is not significant. In light of this, all regions in China follow the same pattern in all of the short-run, the long-run, and the convergence process.

Despite the coefficients of expected housing capital return $\left(a_{3}\right)$ and housing market risk $\left(a_{4}\right)$ of the DFE regression are not significant, their $p$ values are just little bit higher than $10 \%$ significant level in both the DFE and PMG regressions. This case was also found in other papers, and there are two possible reasons. First, the dependent variable, $\Delta \mathrm{lg}$, is quite closed to housing capital return, and then the 
TABLE 3: Nonstationary heterogeneous panel model, decomposed UCC, 2002-2018.

\begin{tabular}{lccc}
\hline Coefficient & Equation $(23)$, DFE & Equation $(24)$, MG & Equation $(25)$, PMG \\
\hline$\beta$ (or $\left.E\left[\beta_{i}\right]\right)$ & $0.715^{* * *}(4.6)$ & $0.913^{* * *}(4.5)$ & $1.032^{* * *}(5.1)$ \\
$\eta\left(\right.$ or $\left.E\left[\eta_{i}\right]\right)$ & $-0.374^{* * *}(10.1)$ & $-0.722^{* * *}(9.8)$ & $-0.513^{* * *}(9.1)$ \\
$a_{1}$ (or $\left.E\left[a_{i 1}\right]\right)$ & $0.807^{* * *}(22.3)$ & $1.006^{* * *}(5.0)$ & $0.835^{* * *}(48.7)$ \\
$a_{2}$ (or $\left.E\left[a_{i 2}\right]\right)$ & $-3.714^{* * *}(2.9)$ & $6.716(0.5)$ & $-4.656^{* * *}(5.2)$ \\
$a_{3}$ (or $\left.E\left[a_{i 3}\right]\right)$ & $0.166(1.6)$ & $0.374^{*}(1.9)$ & $0.088(1.5)$ \\
$a_{4}$ (or $\left.E\left[a_{i 4}\right]\right)$ & $-1.595(1.5)$ & $-7.236(0.5)$ & $-1.027(1.6)$ \\
Constant & $-0.053(0.6)$ & $-0.426^{* * *}(2.7)$ & $-0.215^{* * *}(4.8)$ \\
\hline
\end{tabular}

$|\mathrm{t}|$ given in parentheses; ${ }^{*},{ }^{* *}$, and ${ }^{* * *}$ are significant at $10 \%, 5 \%$, and $1 \%$ levels.

expected housing capital return $\left(r h_{t-1}\right)$ is not significant in ECM structure. Second, in order to empirically exam the form of UCC, the delogarithmic linear decompositions of $\ln$ (UCC) leads to this insignificant case.

The annual housing depreciation rate is commonly assumed to be 0.01 in previous papers (e.g., [1]). Given by the estimated coefficients of the DFE in Table 3 , the ratio between the two estimated coefficients $a_{3} / a_{2}=0.166 / 3.714$ is 0.045 and $a_{4} / a_{2}=-1.595 / 3.714$ is 0.429 . Based on equation (20), rounding all these three numbers, the standard UCC is organized as equation (26). Similarly, with the consideration of housing market risk premium, the UCC ( $\left.\mathrm{UCC}_{\text {risky }}\right)$ is organized as equation (27). We have examined that the DFE regression is more appropriate in describing the China provincial housing data; the empirical relation with logarithmic UCC is given by equation (28):

$$
\begin{gathered}
\mathrm{UCC}(t)=i(t)+0.01-0.05 \cdot \operatorname{rh}(t-1) \\
\mathrm{UCC}_{\text {risky,CRRA }}(t)=i(t)+0.01-0.05 \cdot \operatorname{rh}(t-1)+0.4 \cdot \operatorname{tau}(t) \\
\Delta \lg _{i, t}=\beta_{1} \Delta \operatorname{lry}_{i, t}+\beta_{2} \Delta \ln \left(\mathrm{UCC}_{\text {risky,CRRA }}\right)_{i, t} \\
+\eta\left[\lg _{i, t-1}-a_{1} \operatorname{lry}_{i, t-1}-a_{2} \ln \left(\mathrm{UCC}_{\text {risky,CRRA }}\right)_{i, t-1}\right] \\
+u_{i}+\varepsilon_{i, t} .
\end{gathered}
$$

As shown in Table 4, the consideration of housing market risk makes the significance of the short-run $\ln$ (UCC) parameter $\left(\beta_{2}\right)$ much higher and the goodness-of-fit also increases. Thus, the developed model is more appropriate to be employed in the housing issue analysis. Some once argued that the effect of housing market risk on house price is tiny. Indeed, the direct effect of tau is quite small, but we believe that this direct effect will gradually work through the pricereturn positive circle and completely change the long-run equilibrium of house price. However, because the volatility in price now is self-adjusted, common foresting methods do not work. Therefore, in the next section, simulations are conducted.

\section{Simulation Analysis}

We now proceed to analysis and interpretation of the role that the housing market risk premium plays in dynamic stochastic simulations of the expected utility model. To
TABle 4: Nonstationary heterogeneous panel model, $\ln (\mathrm{UCC})$, 2002-2018.

\begin{tabular}{lcc}
\hline Coefficient & Eq. (28), UCC by $(26)$ & Eq. (28), UCC by $(27)$ \\
\hline$\beta_{1}$ & $0.733^{* * *}(4.6)$ & $0.687^{* * *}(4.4)$ \\
$\beta_{2}$ & $-0.039^{*}(1.9)$ & $-0.063^{* * *}(2.8)$ \\
$\mathrm{H}$ & $-0.427^{* * *}(11.3)$ & $-0.387^{* * *}(10.1)$ \\
$a_{1}$ & $0.821^{* * *}(25.4)$ & $0.791^{* * *}(19.8)$ \\
$a_{2}$ & $-0.217^{* * *}(3.1)$ & $-0.337^{* * *}(3.9)$ \\
Constant & $-0.534^{* * *}(4.2)$ & $-0.568^{* * *}(4.0)$ \\
$R^{2}$ (within) & 0.288 & 0.306 \\
\hline
\end{tabular}

$|\mathrm{t}|$ given in parentheses; ${ }^{*},{ }^{* *}$, and ${ }^{* * *}$ are significant at $10 \%, 5 \%$, and $1 \%$ levels.

summarize, simulation framework consists of two equations: the long-run house price equation and the UCC equation. The long-run house price equation comes from (28) with the empirical estimations given in Table 4 . The UCC equations (26) and (27) are separately applied, where the former is the comparison. $\tau$ is calculated as its CRRA form (19).

Real income is volatile and is the only source of exogenous shocks to house price. Based on RY's statistical mean and standard deviation and simply assuming that its noises are distributed normal, the noises are generated. All of the initial values and growth rates of the variables and parameters also rely on the means given in Table 5. All details are summarized in Appendix F (Table 5).

For comparison, we conduct three curves. The first is based on (28) and (26), and the real income is not volatile in order to show the long-run tendency of house price $(g 1$ series) implied in the standard housing life-cycle model. The second is still based on (28) and (26), but the noises of real income are considered. Then, the generated house price ( $g 2$ series) will also volatile. The third is based on (28) and (27), and the noises are still considered. The difference between $g 2$ and $g 3$ will reflect the effect of housing market risk on longrun house price equilibrium. In $\tau$, the variance of households' expectation is captured by the variance of last four years' housing capital returns.

Notice that calibration simulation (such as the first curve) of the developed expected utility model is meaningless because there is no stochastic element in the calibration simulation and thus the generated $\tau$ becomes to zero. The key to the issue is that the housing market risk relies on the changes in house price inflation from both the exogenous shocks in real income and its self-adjustment. This is the 
TABLE 5: Key values used in the simulations.

\begin{tabular}{|c|c|c|c|}
\hline Parameter & Interpretation & Value & Rationale \\
\hline g_initial & Initial real house price & 35.593 & Sample average (Table 1) \\
\hline HS_cons & Housing sold area (000s) & 5546 & National sample average \\
\hline RC_cons & Real consumption (million) & 10412 & National sample average \\
\hline RY_initial & Initial real income & 142 & Sample average (Table 1) \\
\hline rry_cons & Growth rate of real income & 0.0776 & Sample average (Table 1) \\
\hline std_rry_cons & Standard deviation of rry & 0.0807 & Sample average (Table 1) \\
\hline interest_cons & Nominal interest rate & 0.0525 & Sample average (Table 1) \\
\hline inf_cons & Inflation rate & 0.0248 & Sample average (Table 1) \\
\hline dep_cons & Housing depreciation rate & 0.01 & See text \\
\hline
\end{tabular}

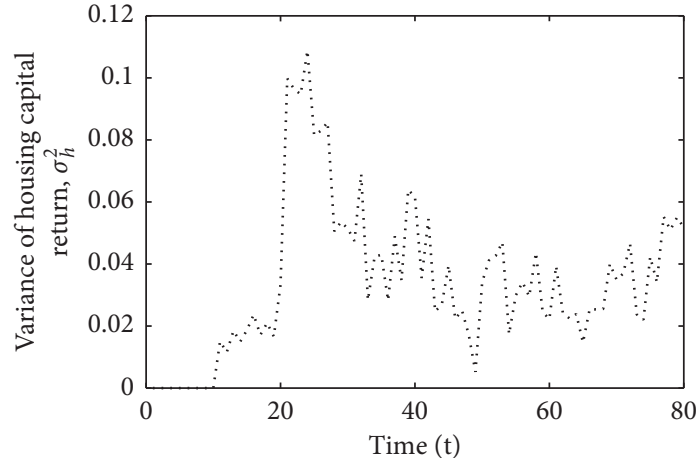

(a)

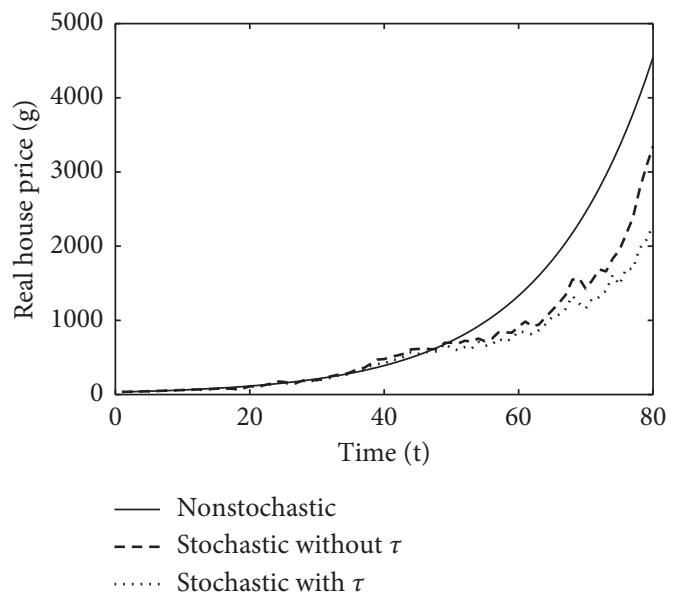

(c)

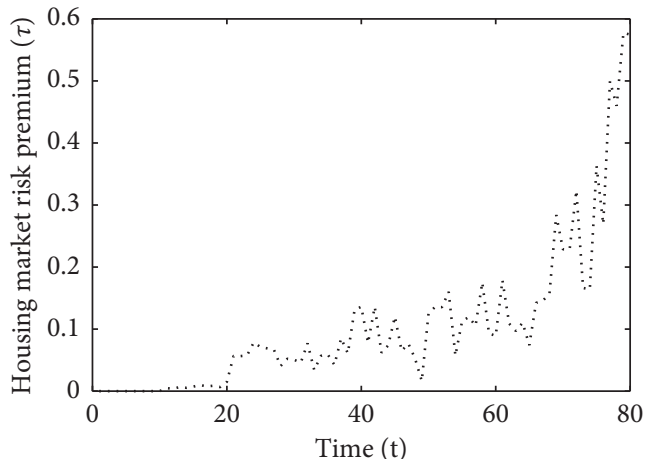

(b)

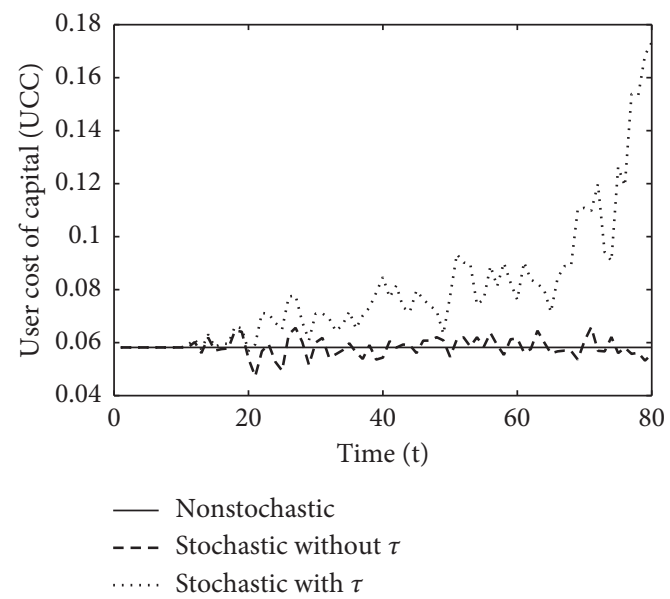

(d)

Figure 1: Dynamics under a single replication (random seed $=1$ ).

reason why the popularly used CGE-type and DSGE-type models cannot reach to our target.

As an initial illustration of the properties, the four frames of Figures 1 and 2 separately plot one realization for the key variables - the variance of housing capital return, housing market risk premium, real house price, and user cost of capital-over 80 years (periods). The differences between these two figures are due to variations in the income series, which is generated by different random seeds (white noise series). Figures generally show that even if the volatility of the housing capital return is stable, housing market risk premium still has an upward trend due to the real house price inflation. The UCC with the consideration of $\tau$ will also has an upward trend, thus limiting the rise in price. In the short-run, the two dynamic house price series have similar dynamic changes because of the same exogenous real income fluctuation. This is the reason why the standard model still works very well in practical data.

The results from a single replication could occur by chance; therefore, repeat the results and average over 100 replications, shown in Figure 3. The results clearly show that because the noises are strongly eliminated, the 


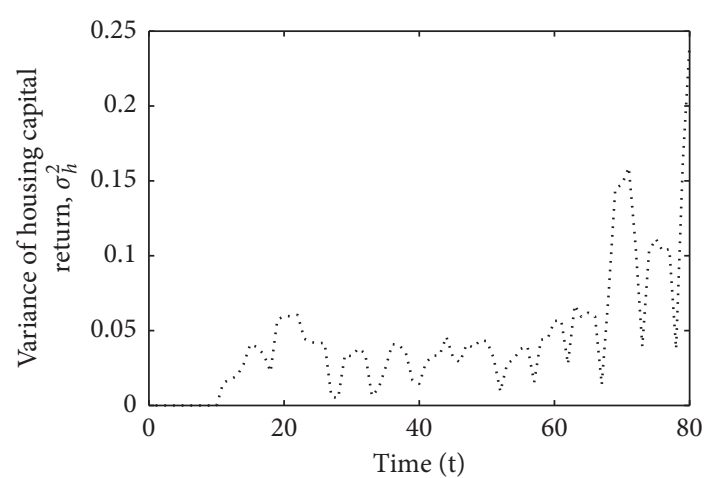

(a)

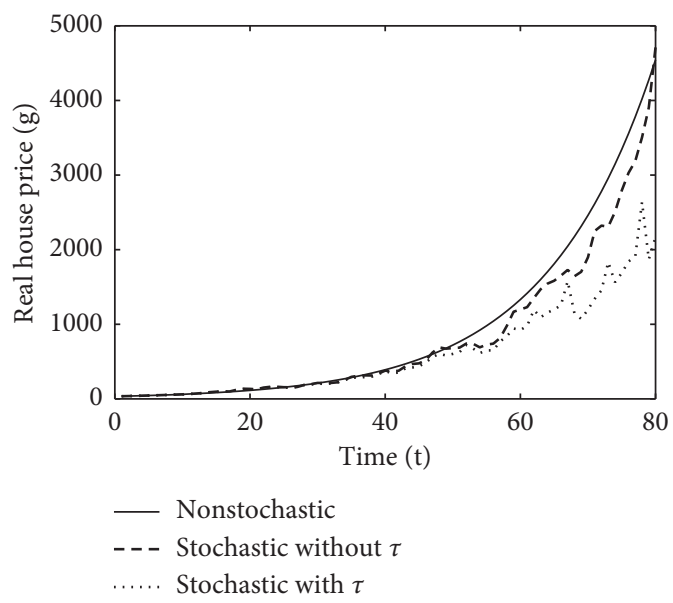

(c)

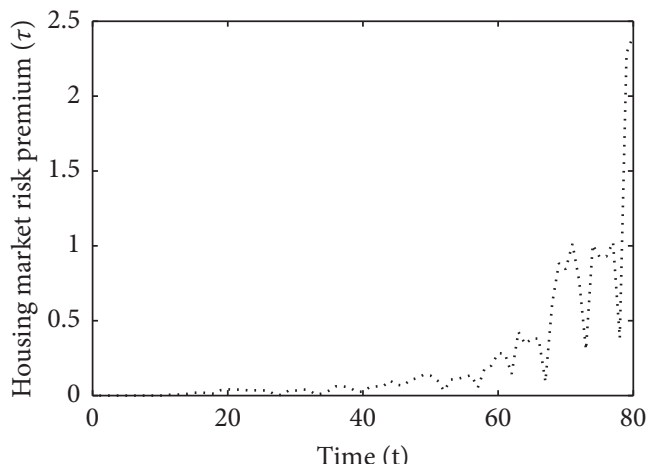

(b)

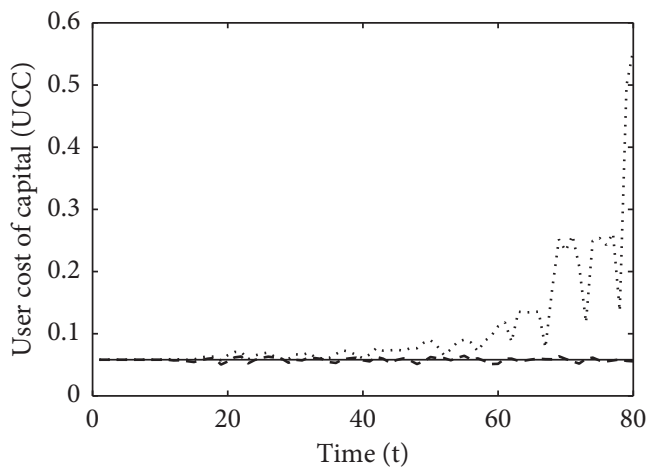

- Nonstochastic

- - - Stochastic without $\tau$

..... Stochastic with $\tau$

(d)

Figure 2: Dynamics under a single replication (random seed $=8$ ).

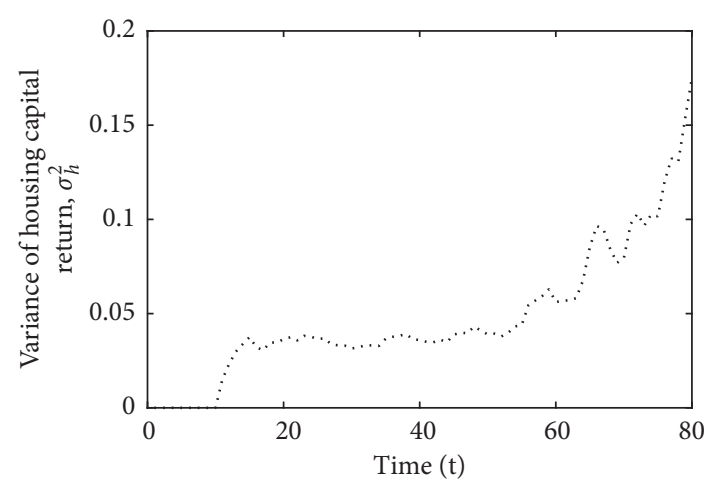

(a)

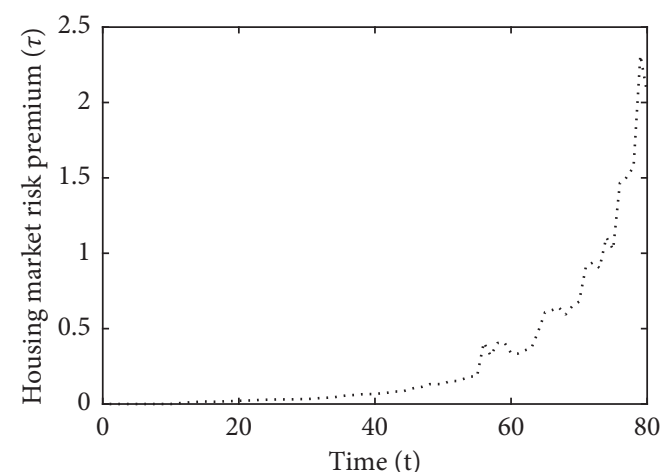

(b)

Figure 3: Continued. 


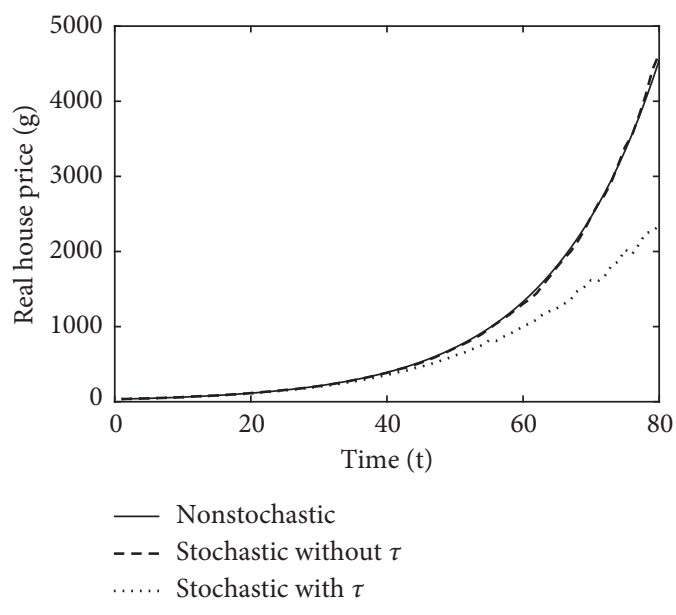

(c)

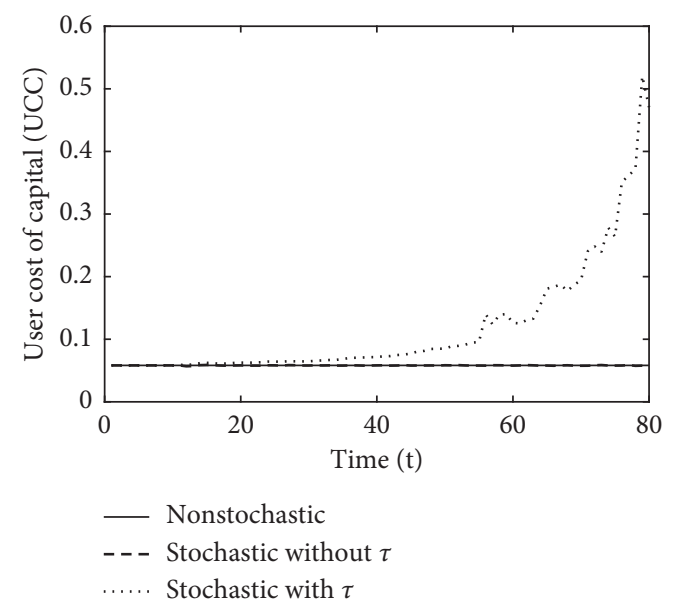

(d)

Figure 3: Average dynamics under 100 replications (random seed: 1-100).

difference in the long-run trends between standard UCC and the UCC with $\tau$ is now significant. First, the average of the real house price fits to the baseline very well, which implies that the consideration of noises is not important to the standard model in forecasting the house price long-run equilibrium. However, when risk is included, simulated house price series is significantly lower than the baseline meaning that the consideration of risk is quite necessary in analyzing house price long-run equilibriums. All these simulations, especially Figure 2, supports our view: house price has a special pattern converges to its long-run equilibrium, where it steadily grows in the booms but sharply reduces in the busts, although the undesirable market collapse is extremely painful.

\section{Conclusion}

This paper provides a number of sections theoretically and empirically focusing on the effect of the housing market risk on house price. A commonly held view is that house prices rarely fall and, therefore, housing is a safe investment. Historical experience appears to bear this out. Lots of studies try to interpret the effect of housing risk on price related to financial theories. However, unlike financial products, house has both consumption and investment properties (demands), and it is very hard to illustrate the consistency between models when financial theories are embedded into economic theory. Risk element cannot be directly introduced into the standard housing model, especially the housing life-cycle model because of the underlying assumption of certainty. To be more realistic, expected housing capital return is redefined to be uncertain and then households maximize the expectation of their uncertain future lifetime utility.
Theoretically, starting at the standard housing lifecycle model, the combined complement method is firstly given in order to show the effect of housing risk on price although the combination between economic and financial theories is still a problem. A fully developed expected utility housing life-cycle model is given, which is purely economic-based, and one of its specific derivations is identical to the equation derived from the combined complement method. The results imply that the effect of the housing market risk-the risk-aversion parameter times real housing value and times housing volatility-is positive to UCC and is negative to house price. Given on the specific CRRA housing market risk derivation and relying on the China housing data, empirical results support our definition of the housing market risk premium.

Based on the empirical results, simulations are given in order to check whether housing market risk could have significant impact on house price long-run equilibriums. The results clearly show that, with the inclusion of housing market risk, long-run house price is no long terribly high compared with the implication derived from the standard housing life-cycle model. Evidences support the view that house price steadily grows in the common periods but backward adjusted through housing market catastrophe.

Finally, for the purpose of keeping house price more stable and reducing the probability of housing market collapse, we suggest that (i) governments can increase the feedback effect of risk on price through policies and systems such as housing security; (ii) governments can also promote residences' risk perception through news and media; (iii) governments can smooth price cycles by the contracyclical regulation. 


\section{Appendix}

\section{A. The standard housing life-cycle model}

The lifetime utility function and constraints:

$$
\begin{aligned}
& \int_{0}^{\infty} e^{-r t} \mu[H(t), C(t)] \mathrm{d} t \\
& g(t) X(t)+S(t)+C(t)=R Y(t)+i(t) A(t), \\
& \dot{H}(t)=X(t)-\delta(t) H(t), \\
& \dot{A}(t)=S(t)-\pi(t) A(t) .
\end{aligned}
$$

The households' lifetime housing decision can be found from maximizing the following Hamiltonian function:

$$
\begin{aligned}
\mathscr{L}(t)= & \int_{0}^{\infty} e^{-r t}\{\mu[H(t), C(t)]+\lambda(t)[\mathrm{RY}(t)-g(t)[\dot{H}(t) \\
& +\delta(t) H(t)+[i(t)-\pi(t)] A(t)-\dot{A}(t)-C(t)]]\} \mathrm{d} t .
\end{aligned}
$$

The first-order conditions are as follows:

$$
\frac{\partial \mathscr{L}(t)}{\partial H(t)}=e^{-r t} \mu_{H}(t)-e^{-r t} \lambda(t) g(t) \delta(t)+\frac{\mathrm{d}}{\mathrm{d} t}\left[e^{-r t} \lambda(t) g(t)\right]=0,
$$

$\frac{\partial \mathscr{L}(t)}{\partial C(t)}=e^{-r t} \mu_{C}(t)-e^{-r t} \lambda(t)=0$,

$\frac{\partial \mathscr{L}(t)}{\partial A(t)}=e^{-r t} \lambda(t)[i(t)-\pi(t)]+\frac{\mathrm{d}}{\mathrm{d} t}\left[e^{-r t} \lambda(t)\right]=0$

From (A.4),

$$
\mu_{C}(t)=\lambda(t)
$$

From (A.3),

$$
\begin{aligned}
e^{-r t} \mu_{H}(t)= & e^{-r t} \lambda(t) g(t) \delta(t)-\frac{\mathrm{d}}{\mathrm{d} t}\left[e^{-r t} \lambda(t) g(t)\right], \\
e^{-r t} \mu_{H}(t)= & e^{-r t} \lambda(t) g(t) \delta(t)-\dot{g}(t) e^{-r t} \lambda(t) \\
& -g(t) \frac{\mathrm{d}}{\mathrm{d} t}\left[e^{-r t} \lambda(t)\right],
\end{aligned}
$$

where $\dot{g}(t)=\mathrm{d} g(t) / \mathrm{d} t$.

Substituting (A.5) and (A.6) into (A.7),

$$
\begin{aligned}
e^{-r t} \mu_{H}(t)= & e^{-r t} \mu_{C}(t) g(t) \delta(t)-\dot{g}(t) e^{-r t} \mu_{C}(t) \\
& -g(t) e^{-r t} \mu_{C}(t)[i(t)-\pi(t)] .
\end{aligned}
$$

Then,

$$
\begin{aligned}
& \frac{\mu_{H}(t)}{\mu_{C}(t)}=g(t) \delta(t)-\dot{g}(t)+[i(t)-\pi(t)] g(t), \\
& \frac{\mu_{H}(t)}{\mu_{C}(t)}=\left[i(t)-\pi(t)+\delta(t)-r_{H}(t)\right] g(t),
\end{aligned}
$$

where $r_{H}(t)=\dot{g}(t) / g(t)$.

\section{B. The equivalence between risky and riskless houses}

Conditions:

$$
\begin{aligned}
\mu\left[\left(1+r_{H, \text { free }}\right) \mathrm{HW}\right] & =E\left\{\mu\left[\left(1+r_{H, \text { risky }}\right) \mathrm{HW}\right]\right\}, \\
r_{H, \text { risky }} & \sim N\left[r_{H, \text { risky }}^{e}, \sigma_{H, \text { risky }}^{2}\right], \\
\mu[x] & =-\exp [-\gamma x] .
\end{aligned}
$$

Rewrite the generalized equivalent under the CARA utility:

$$
\begin{aligned}
& -\exp \left[-\gamma\left(1+r_{H, \text { free }}\right) \mathrm{HW}\right]=E\{-\exp \\
& \left.\cdot\left[-\gamma\left(1+r_{H, \text { risky }}\right) \mathrm{HW}\right]\right\} .
\end{aligned}
$$

Then, include (B.2):

$$
\begin{aligned}
& \exp \left[-\gamma\left(1+r_{H, \text { free }}\right) \mathrm{HW}\right]=\int_{-\infty}^{+\infty}\left\{\operatorname { e x p } \left[-\gamma\left(1+r_{H, \text { risky }}^{e}\right.\right.\right. \\
& \left.\left.\left.+\sigma_{H, \text { risky }} z\right) \mathrm{HW}\right] \phi(z)\right\} d(z),
\end{aligned}
$$

where $\phi(z)=(1 / \sqrt{2 \pi}) \exp \left[-0.5 z^{2}\right]$, the standard normal probability density function for $z$ ).

Then, 


$$
\begin{aligned}
& \exp \left[-\gamma\left(1+r_{H, \text { free }}\right) H W\right] \\
& =\int_{-\infty}^{+\infty}\left\{\exp \left[-\gamma\left(1+r_{H, \text { risky }}^{e}+\sigma_{H, \text { risky }} z\right) \mathrm{HW}\right]\left(\frac{1}{\sqrt{2 \pi}}\right) \exp \left[-0.5 z^{2}\right]\right\} d(z) \\
& =\exp \left[-\gamma\left(1+r_{H, \text { risky }}^{e}\right)\right] \int_{-\infty}^{+\infty}\left\{\exp \left[-\gamma \mathrm{HW} \sigma_{H, \text { risky }} z\right]\left(\frac{1}{\sqrt{2 \pi}}\right) \exp \left[-0.5 z^{2}\right]\right\} d(z) \\
& =\exp \left[-\gamma\left(1+r_{H, \text { risky }}^{e}\right)\right] \int_{-\infty}^{+\infty}\left\{\left(\frac{1}{\sqrt{2 \pi}}\right) \exp \left[-\gamma \mathrm{HW} \sigma_{H, \text { risky }} z-0.5 z^{2}\right]\right\} d(z) \\
& =\exp \left[-\gamma\left(1+r_{H, \text { risky }}^{e}\right)\right] \exp \left[0.5\left(\gamma \mathrm{HW} \sigma_{H, \text { risky }}\right)^{2}\right] \\
& \cdot \int_{-\infty}^{+\infty}\left\{\left(\frac{1}{\sqrt{2 \pi}}\right) \exp ^{+\infty}\left[-0.5\left(z^{2}+2 \gamma \mathrm{HW} \sigma_{H, \text { risky }} z+\left(\gamma \mathrm{HW} \sigma_{H, \text { risky }}\right)^{2}\right]\right\} d(z)\right. \\
& =\exp \left[-\gamma\left(1+r_{H, \text { risky }}^{e}\right)+0.5\left(\gamma \mathrm{HW} \sigma_{H, \text { risky }}\right)^{2}\right] . \\
& =\exp \left[-\gamma\left(1+r_{H, \text { risky }}^{e}\right)\right] \exp \left[0.5\left(\gamma \mathrm{HW} \sigma_{H, \text { risky }}\right)^{2}\right]
\end{aligned}
$$

Therefore,

$$
U=E\left\{\int_{0}^{\infty} e^{-r t} \mu[H(t), C(t)] \mathrm{d} t\right\}
$$

$$
\begin{aligned}
-\gamma\left(1+r_{H, \text { free }}\right) \mathrm{HW} & =-\gamma\left(1+r_{H, \text { risky }}^{e}\right) \mathrm{HW}+0.5\left(\gamma \mathrm{HW} \sigma_{H, \text { risky }}\right)^{2} \\
1+r_{H, \text { free }} & =\left(1+r_{H, \text { risky }}^{e}\right)-0.5 \gamma \mathrm{HW} \sigma_{H, \text { risky }}^{2} \\
r_{H, \text { free }} & =r_{H, \text { risky }}^{e}-0.5 \gamma \mathrm{HW} \sigma_{H, \text { risky }}^{2}
\end{aligned}
$$$$
g(t) X(t)+S(t)+C(t)=R Y(t)+i(t) A(t),
$$$$
\dot{H}(t)=X(t)-\delta(t) H(t),
$$

$$
\dot{A}(t)=S(t)-\pi(t) A(t) .
$$

\section{The two-asset expected utility housing life- cycle model}

The households' lifetime housing decision can be found

The lifetime utility function and constraints:

$$
\mathscr{L}(t)=E\left\{\int_{0}^{\infty} e^{-r t}\{\mu[H(t), C(t)]+\lambda(t)[\mathrm{RY}(t)-g(t)[\dot{H}(t)+\delta(t) H(t)]+[i(t)-\pi(t)] A(t)-\dot{A}(t)-C(t)] \mathrm{d} t\}\right\} .
$$

The first-order conditions are as follows:

$$
\frac{\partial \mathscr{L}(t)}{\partial A(t)}=E\left\{e^{-r t} \lambda(t)[i(t)-\pi(t)]+\frac{\mathrm{d}}{\mathrm{d} t}\left[e^{-r t} \lambda(t)\right]\right\}=0 .
$$

$$
\frac{\partial \mathscr{L}(t)}{\partial H(t)}=E\left\{e^{-r t} \mu_{H}(t)-e^{-r t} \lambda(t) g(t) \delta(t)+\frac{\mathrm{d}}{\mathrm{d} t}\left[e^{-r t} \lambda(t) g(t)\right]\right\}=0
$$

$\frac{\partial \mathscr{L}(t)}{\partial C(t)}=E\left\{e^{-r t} \mu_{C}(t)-e^{-r t} \lambda(t)\right\}=0$

(Notice that all variables are certain at time period $(t)$ and uncertain in the future $(t+\mathrm{d} t, t+2 \mathrm{~d} t, t+3 \mathrm{~d} t, \ldots)$. So, certain elements can be removed to the outside of expectations.) 
From (C.7),

$$
E\left[\mu_{C}(t)\right]=E[\lambda(t)]
$$

From (C.6),

$$
\begin{aligned}
E\left[e^{-r t} \mu_{H}(t)\right]= & E\left[e^{-r t} \lambda(t) g(t) \delta(t)\right]-E\left[\frac{\mathrm{d}}{\mathrm{d} t}\left[e^{-r t} \lambda(t) g(t)\right]\right], \\
e^{-r t} E\left[\mu_{H}(t)\right]= & e^{-r t} E[\lambda(t)] g(t) \delta(t)-E\left[\dot{g}(t) e^{-r t} \lambda(t)\right. \\
& \left.-g(t) \frac{\mathrm{d}}{\mathrm{d} t}\left[e^{-r t} \lambda(t)\right]\right],
\end{aligned}
$$

where $\dot{g}(t)=\mathrm{d} g(t) / \mathrm{d} t=g(t+\mathrm{d} t)-g(t)$.

Substituting (C.8) and (C.9) into (C 10), we obtain

$$
\begin{aligned}
e^{-r t} E\left[\mu_{H}(t)\right]= & e^{-r t} E\left[\mu_{C}(t)\right] g(t) \delta(t)-e^{-r t} g(t) E\left[r_{H, \text { risky }}(t) \mu_{C}(t)\right] \\
& -g(t) e^{-r t} E\left[\mu_{C}(t)\right][i(t)-\pi(t)],
\end{aligned}
$$

where $r_{H \text {,risky }}(t)=\dot{g}(t) / g(t)$.

Then,

$$
\begin{aligned}
& \frac{E\left[\mu_{H}(t)\right]}{E\left[\mu_{C}(t)\right]}=g(t) \delta(t)+[i(t)-\pi(t)] g(t)-g(t) \frac{E\left[r_{H, \text { risky }}(t) \mu_{C}(t)\right]}{E\left[\mu_{C}(t)\right]}, \\
& \frac{E\left[\mu_{H}(t)\right]}{E\left[\mu_{C}(t)\right]}=\left[i(t)-\pi(t)+\delta(t)-\frac{E\left[r_{H, \text { risky }}(t) \mu_{C}(t)\right]}{E\left[\mu_{C}(t)\right]}\right] g(t) .
\end{aligned}
$$

\section{The two-asset expected utility housing life- cycle model under CARA utility conditions:}

$$
\begin{gathered}
r_{H, \text { risky }} \sim N\left[r_{H, \text { risky }}^{e}, \sigma_{H, \text { risky }}^{2}\right], \\
\mu[H(t), C(t)]=-\exp [-\phi H(t)]-\exp [-\phi C(t)] .
\end{gathered}
$$

Equations (C.2)-(C.4) can be organized as one equation:

$$
\begin{aligned}
C(t)= & \mathrm{RY}(t)+i(t) A(t)-g(t)[\dot{H}(t)+\delta(t) H(t)] \\
& -\dot{A}(t)-\pi(t) A(t),
\end{aligned}
$$

or

$$
\begin{aligned}
C(t) \approx & R Y(t)+\left[r_{H, \text { risky }}(t)-\delta(t)\right] g(t) H(t) \\
& +[i(t)-\pi(t)] A(t)
\end{aligned}
$$

This equation implies that if people do not want to change the quantities of their housing and nonhousing assets, all of their labour income, housing net yield, and nonhousing financial yield will be consumed.

Also, because housing net yield is uncertain due to the uncertain house price inflation rate, household expected consumption is given by

$$
\begin{aligned}
E[C(t)]= & C^{e}(t)=\mathrm{RY}(t)+\left[r_{H, \text { risky }}^{e}(t)-\delta(t)\right] g(t) H(t) \\
& +[i(t)-\pi(t)] A(t) .
\end{aligned}
$$

Remember that, to derive specific solution of equation (C.12), we need to solve $E\left[\mu_{C}(t)\right]$ and $E\left[r_{H \text {,risky }}(t) \mu_{C}(t)\right]$ based on equation (D.5).

Step 1: the derivation of $E\left[\mu_{C}(t)\right]$ :

$$
E\left[\mu_{C}(t)\right]=\int_{-\infty}^{+\infty}\left\{\mu_{C}(t) \phi(z)\right\} \mathrm{d}(z)
$$

where $\phi(z)=(1 / \sqrt{2 \pi}) \exp \left[-0.5 z^{2}\right]$, the standard normal probability density function for $\mathrm{z}$.

$$
\begin{aligned}
& \text { So, } E\left[\mu_{C}(t)\right]=\int_{-\infty}^{+\infty}\{\phi \exp [-\phi C(t)] \phi(z)\} \mathrm{d}(z) \\
& =\int_{-\infty}^{+\infty}\left\{\phi \exp \left[-\phi C^{e}(t)-\phi g(t) H(t) \sigma_{H, \text { risky }}(t) z\right] \phi(z)\right\} \mathrm{d}(z) \\
& =\phi \exp \left[-\phi C^{e}(t)\right] \int_{-\infty}^{+\infty}\left\{\exp \left[-\phi g(t) H(t) \sigma_{H, \text { risky }}(t) z\right]\right. \\
& \left.\cdot\left(\frac{1}{\sqrt{2 \pi}}\right) \exp \left[-0.5 z^{2}\right]\right\} \mathrm{d}(z) \\
& =\phi \exp \left[-\phi C^{e}(t)\right] \exp \left[0.5\left(\phi g(t) H(t) \sigma_{H, \text { risky }}(t)\right)^{2}\right]
\end{aligned}
$$

Method of deriving the final equation is the same as Appendix B.

Therefore,

$$
\begin{aligned}
E\left[\mu_{C}(t)\right]= & \phi \exp \left[-\phi C^{e}(t)\right] \\
& \cdot \exp \left[0.5\left(\phi g(t) s H(t) \sigma_{H, \text { risky }}(t)\right)^{2}\right] .
\end{aligned}
$$

Step 2: the derivation of $E\left[r_{H \text {,risky }}(t) \mu_{C}(t)\right]$ : 


$$
\begin{aligned}
& E\left[r_{H, \text { risky }}(t) \mu_{C}(t)\right]=\int_{-\infty}^{+\infty}\left\{\left[r_{H, \text { risky }}^{e}(t)+\sigma_{H, \text { risky }} z\right] \mu_{C}(t) \phi(z)\right\} \mathrm{d}(z) \\
& =\int_{-\infty}^{+\infty}\left\{r_{H, \text { risky }}^{e}(t) \mu_{C}(t) \phi(z)+\sigma_{H, \text { risky }} z \mu_{C}(t) \phi(z)\right\} \mathrm{d}(z) \\
& =r_{H, \text { risky }}^{e}(t) E\left[\mu_{C}(t)\right]+\int_{-\infty}^{+\infty}\left\{\sigma_{H, \text { risky }} z \mu_{C}(t) \phi(z)\right\} \mathrm{d}(z) \\
& =r_{H, \text { risky }}^{e}(t) E\left[\mu_{C}(t)\right]+\int_{-\infty}^{+\infty}\left\{\sigma_{H, \text { risky }} z \phi \exp \left[-\phi C^{e}(t)-\phi g(t) H(t) \sigma_{H, \text { risky }}(t) z\right]\left(\frac{1}{\sqrt{2 \pi}}\right) \exp \left[-0.5 z^{2}\right]\right\} \mathrm{d}(z) \\
& =r_{H, \text { risky }}^{e}(t) E\left[\mu_{C}(t)\right]+\sigma_{H, \text { risky }} \phi \exp \left[-\phi C^{e}(t)\right] \int_{-\infty}^{+\infty}\left\{z\left(\frac{1}{\sqrt{2 \pi}}\right)\right. \\
& \left.\exp \left[-\phi g(t) H(t) \sigma_{H, \text { risky }}(t) z\right] \exp \left[-0.5 z^{2}\right]\right\} \mathrm{d}(z) \\
& =r_{H, \text { risky }}^{e}(t) E\left[\mu_{C}(t)\right]+\sigma_{H, \text { risky }} \phi \exp \left[-\phi C^{e}(t)\right] \exp \left[0.5\left(\phi g(t) H(t) \sigma_{H, \text { risky }}(t)\right)^{2}\right] \\
& =\int_{-\infty}^{+\infty}\left\{z\left(\frac{1}{\sqrt{2 \pi}}\right) \exp \left[-0.5\left(z+\phi g(t) H(t) \sigma_{H, \text { risky }}(t)\right)^{2}\right]\right\} \mathrm{d}(z) \\
& =r_{H, \text { risky }}^{e}(t) E\left[\mu_{C}(t)\right]+\sigma_{H, \text { risky }} \phi \exp \left[-\phi C^{e}(t)\right] \exp \left[0.5\left(\phi g(t) H(t) \sigma_{H, \text { risky }}(t)\right)^{2}\right] \\
& \left.\int_{H, \text { risky }}(t)\right] .
\end{aligned}
$$

Therefore,

$$
\begin{gathered}
E\left[r_{H, \text { risky }}(t) \mu_{C}(t)\right]=r_{H, \text { risky }}^{e}(t) E\left[\mu_{C}(t)\right]+\sigma_{H, \text { risky }} \phi \exp \left[-\phi C^{e}(t)\right] \\
\cdot \exp \left[0.5\left(\phi g(t) H(t) \sigma_{H, \text { risky }}(t)\right)^{2}\right] \cdot\left[-\phi g(t) H(t) \sigma_{H, \text { risky }}(t)\right] .
\end{gathered}
$$

Step 3: calculate the UCC as well as tau $(\boldsymbol{\tau})$ under CARA.

Combine (D.9) and (D.10):

$\frac{E\left[r_{H, \text { risky }}(t) \mu_{C}(t)\right]}{E\left[\mu_{C}(t)\right]}=r_{H, \text { risky }}^{e}(t)-\phi g(t) H(t) \sigma_{H, \text { risky }}^{2}(t)$.

Substitute (D.11) into (D.12):

$$
\begin{aligned}
& \frac{E\left[\mu_{H}(t)\right]}{E\left[\mu_{C}(t)\right]}=\left[i(t)-\pi(t)+\delta(t)-r_{H, \text { risky }}^{e}(t)\right. \\
& \left.\quad+\phi g(t) H(t) \sigma_{H, \text { risky }}^{2}(t)\right] g(t) .
\end{aligned}
$$

So,

$$
\begin{aligned}
\mathrm{UCC}_{\mathrm{CARA}} & =i(t)-\pi(t)+\delta(t)-r_{H, \text { risky }}^{e}(t)+\tau(t), \\
\tau_{\mathrm{CARA}} & =\phi g(t) H(t) \sigma_{H, \text { risky }}^{2}(t) .
\end{aligned}
$$

\section{E. The two-asset expected utility housing life- cycle model under CRRA utility conditions:}

$$
\begin{gathered}
r_{H, \text { risky }} \sim N\left[r_{H, \text { risky }}^{e}, \sigma_{H, \text { risky }}^{2}\right], \\
\mu[H(t), C(t)]=\frac{H(t)^{(1-\theta)}}{1-\theta}+\frac{C(t)^{(1-\theta)}}{1-\theta} .
\end{gathered}
$$

As $\phi(z)=(1 / \sqrt{2 \pi}) \exp \left[-0.5 z^{2}\right]$ is the standard normal probability density function for $z$, there are three related useful mathematical theorems:

(1) Constant: $\int_{-\infty}^{+\infty} c \cdot \phi(z) \mathrm{d} z=c$

(2) Constant $\times$ mean: $\int_{-\infty}^{+\infty} c z \cdot \phi(z) \mathrm{d} z=c \cdot 0=0$

(3) Constant $\times$ variance: $\int_{-\infty}^{+\infty} c z^{2} \cdot \phi(z) \mathrm{d} z=c \cdot 1=c$

The marginal utility of consumption under CRRA is

$$
\mu_{C}(t)=C(t)^{-\theta} \text {. }
$$

Based on all the above conditions and mathematical theorems, solve $E\left[\mu_{C}(t)\right]$ and $E\left[r_{H \text {,risky }}(t) \mu_{C}(t)\right]$ in order to derive the specific derivation of equation (D.12). 
Step 1: the derivation of $E\left[\mu_{C}(t)\right]$ :

Take a second-order Taylor expression of $\mu_{C}(t)$, where $C(t)=C^{e}(t)$ :

$$
\begin{gathered}
C(t)^{-\theta} \approx C^{e}(t)^{-\theta}-\theta C^{e}(t)^{-\theta-1}\left[C(t)-C^{e}(t)\right] \\
+0.5 \theta(\theta+1) C^{e}(t)^{-\theta-2}\left[C(t)-C^{e}(t)\right]^{2} .
\end{gathered}
$$

Then,

$$
\begin{aligned}
& E\left[\mu_{C}(t)\right] \\
&=\int_{-\infty}^{+\infty}\left\{\mu_{C}(t) \phi(z)\right\} d(z) \\
&=\int_{-\infty}^{+\infty}\left\{\left[C(t)^{-\theta}\right] \phi(z)\right\} d(z) \\
& \approx \int_{-\infty}^{+\infty}\left\{\left[C^{e}(t)^{-\theta}-\theta C^{e}(t)^{-\theta-1}\left[g(t) H(t) \sigma_{H, \text { risky }}(t) z\right]\right.\right. \\
&\left.\left.+0.5 \theta(\theta+1) C^{e}(t)^{-\theta-2}\left[g(t) H(t) \sigma_{H, \text { risky }}(t) z\right]^{2}\right] \phi(z)\right\} d(z) \\
& \approx \int_{-\infty}^{+\infty}\left\{C^{e}(t)^{-\theta} \phi(z)\right\} d(z)+\int_{-\infty}^{+\infty} \\
& \cdot\left\{-\theta C^{e}(t)^{-\theta-1}\left[g(t) H(t) \sigma_{H, \text { risky }}(t) z\right] \phi(z)\right\} d(z) \\
&+\int_{-\infty}^{+\infty}\left\{0.5 \theta(\theta+1) C^{e}(t)^{-\theta-2}\left[g(t) H(t) \sigma_{H, \text { risky }}(t) z\right]^{2} \phi(z)\right\} d(z) \\
& \approx C^{e}(t)^{-\theta}+0.5 \theta(\theta+1) C^{e}(t)^{-\theta-2}\left[g(t) H(t) \sigma_{H, \text { risky }}(t)\right]^{2} .
\end{aligned}
$$

Step 2: the derivation of $E\left[r_{H \text {,risky }}(t) \mu_{C}(t)\right]$ :

Take a second-order Taylor expression of $r_{H \text {,risky }}(t) \mu_{C}(t)$, where $\quad C(t)=C^{e}(t) \quad$ and $r_{H, \text { risky }}(t)=r_{H, \text { risky }}^{e}(t)$ :

$$
\begin{aligned}
& r_{H, \text { risky }}(t) C(t)^{-\theta} \approx r_{H, \text { risky }}^{e}(t) C^{e}(t)^{-\theta} \\
& +\left[r_{H, \text { risky }}(t)-r_{H, \text { risky }}^{e}(t)\right] C^{e}(t)^{-\theta} \\
& +r_{H, \text { risky }}^{e}(t)(-\theta) C^{e}(t)^{-\theta-1}\left[C(t)-C^{e}(t)\right] \\
& +r_{H, \text { risky }}^{e}(t) 0.5 \theta(\theta+1) C^{e}(t)^{-\theta-2}\left[C(t)-C^{e}(t)\right]^{2} \\
& +(-\theta) C^{e}(t)^{-\theta-1}\left[C(t)-C^{e}(t)\right]\left[r_{H, \text { risky }}(t)-r_{H, \text { risky }}^{e}(t)\right] .
\end{aligned}
$$

Then, $E\left[r_{H, \text { risky }}(t) \mu_{C}(t)\right]$

$$
\begin{aligned}
\approx & \int_{-\infty}^{+\infty}\left\{r_{H, \text { risky }}^{e}(t) C^{e}(t)^{-\theta}+\left[\sigma_{H, \text { risky }}(t) z\right] C^{e}(t)^{-\theta}\right. \\
& +r_{H, \text { risky }}^{e}(t)(-\theta) C^{e}(t)^{-\theta-1}\left[g(t) H(t) \sigma_{H, \text { risky }}(t) z\right] \\
& +r_{H, \text { risky }}^{e}(t) 0.5 \theta(\theta+1) C^{e}(t)^{-\theta-2}\left[g(t) H(t) \sigma_{H, \text { risky }}(t) z\right]^{2} \\
& \left.+(-\theta) C^{e}(t)^{-\theta-1}\left[g(t) H(t) \sigma_{H, \text { risky }}(t) z\right]\left[\sigma_{H, \text { risky }}(t) z\right]\right\} \phi(z) \mathrm{d}(z) \\
\approx & r_{H, \text { risky }}^{e}(t) C^{e}(t)^{-\theta}+r_{H, \text { risky }}^{e}(t) 0.5 \theta(\theta+1) \\
& \cdot C^{e}(t)^{-\theta-2}\left[g(t) H(t) \sigma_{H, \text { risky }}(t)\right]^{2} \\
& +(-\theta) C^{e}(t)^{-\theta-1}\left[g(t) H(t) \sigma_{H, \text { risky }}^{2}(t)\right] .
\end{aligned}
$$

Step 3: calculate the UCC as well as tau $(\boldsymbol{\tau})$ under CRRA Combine the results from Steps 1 and 2:

$$
\begin{aligned}
& \frac{E\left[r_{H, \text { risky }}(t) \mu_{C}(t)\right]}{E\left[\mu_{C}(t)\right]}=r_{H, \text { risky }}^{e}(t) \\
& -\frac{-\theta C^{e}(t)^{-\theta-1} g(t) H(t) \sigma_{H, \text { risky }}^{2}(t)}{E\left[\mu_{C}(t)\right]},
\end{aligned}
$$

or

$$
\begin{aligned}
& \frac{E\left[r_{H, \text { risky }}(t) \mu_{C}(t)\right]}{E\left[\mu_{C}(t)\right]}=r_{H, \text { risky }}^{e}(t) \\
& -\frac{-\theta C^{e}(t)^{-\theta-1}}{E\left[C(t)^{-\theta}\right]} g(t) H(t) \sigma_{H, \text { risky }}^{2}(t) .
\end{aligned}
$$

If expectations are ignored, $\left\{-\theta C^{e}(t)^{-\theta-1}\right\} /\{E$ $\left.\left[C(t)^{-\theta}\right]\right\}=\theta / C(t)$; it will be the Pratt-Arrow coefficient for CRRA utility under certainty $\left(-\left(\mu_{C}^{\prime \prime}(t) / \mu_{C}^{\prime}(t)\right)=(\theta / C(t))\right)$.

Under this approximation, substituting (E.9) into (D.12), we obtain

$$
\begin{aligned}
\mathrm{UCC}_{\mathrm{CRRA}} & =i(t)-\pi(t)+\delta(t)-r_{H, \text { risky }}^{e}(t)+\tau(t), \\
\tau_{\mathrm{CRRA}} & =\left[\frac{\theta}{C(t)}\right] g(t) H(t) \sigma_{H, \text { risky }}^{2}(t) .
\end{aligned}
$$

Notice that the coefficient of the uncertain utility $\left(\left\{-\theta C^{e}(t)^{-\theta-1}\right\} /\left\{E\left[C(t)^{-\theta}\right]\right\}\right.$ is still solvable, but because (i) national risk attitude is relatively stable, (ii) the difference with $\theta / C(t)$ is tiny, and (iii) the similar pattern with $\tau_{C A R A}$ derivation, the approximation is more meaningful.

\section{F. Key values used in the simulations}

Further details and the complete replication of our results are available via our MATLAB simulation codes, which can be provided.

\section{Data Availability}

The data used to support the findings of this study are available from the corresponding author upon request.

\section{Conflicts of Interest}

The authors declare that there are no conflicts of interest regarding the publication of this paper.

\section{Acknowledgments}

This research was supported by Shandong Social Science Planning Research Project (China) (grant no. 19DTJJ02). 


\section{References}

[1] G. Meen, Modelling Spatial Housing Markets: Theory, Analysis, and Policy, Vol. 2, Springer Science \& Business Media, Berlin, Germany, 2001.

[2] J. G. Nellis and J. A. Longbottom, "An empirical analysis of the determination of house prices in the United Kingdom," Urban Studies, vol. 18, no. 1, pp. 9-21, 1981.

[3] J. M. Poterba, "Tax subsidies to owner-occupied housing: an asset-market approach," The Quarterly Journal of Economics, vol. 99, no. 4, pp. 729-752, 1984.

[4] D. DiPasquale and W. C. Wheaton, "Housing market dynamics and the future of housing prices," Journal of Urban Economics, vol. 35, no. 1, pp. 1-27, 1994.

[5] A. Can, "Specification and estimation of hedonic housing price models," Regional Science and Urban Economics, vol. 22, no. 3, pp. 453-474, 1992.

[6] A. Dougherty and R. Van Order, "Inflation, housing costs, and the consumer price index," American Economic Review, vol. 72, pp. 154-164, 1982.

[7] G. P. Meen, "The removal of mortgage market constraints and the implications for econometric modelling of UK house prices," Oxford Bulletin of Economics and Statistics, vol. 52, no. 1, pp. 1-23, 1990.

[8] J. Muellbauer and A. Murphy, "Booms and busts in the UK housing market," The Economic Journal, vol. 107, no. 445, pp. 1701-1727, 1997.

[9] J. M. Poterba, D. N. Weil, and R. Shiller, "House price dynamics: the role of tax policy and demography," Brookings Papers on Economic Activity, vol. 1991, no. 2, pp. 143-203, 1991.

[10] N. G. Mankiw and D. N. Weil, "The baby boom, the baby bust, and the housing market," Regional Science and Urban Economics, vol. 19, no. 2, pp. 235-258, 1989.

[11] H. Markowitz, "Portfolio selection," The Journal of Finance, vol. 7, no. 1, pp. 77-91, 1952.

[12] J. Lintner, "The valuation of risk assets and the selection of risky investments in stock portfolios and capital budgets," The Review of Economics and Statistics, vol. 47, no. 1, pp. 13-37, 1965.

[13] W. F. Sharpe, "Mutual fund performance," The Journal of Business, vol. 39, no. S1, pp. 119-138, 1966.

[14] F. Black, "Capital market equilibrium with restricted borrowing," The Journal of Business, vol. 45, no. 3, pp. 444-455, 1972.

[15] E. Fama, "Multiperiod consumption-investment decisions," American Economic Review, vol. 60, pp. 163-174, 1970.

[16] E. F. Fama and K. R. French, "Common risk factors in the returns on stocks and bonds," Journal of Financial Economics, vol. 33, no. 1, pp. 3-56, 1993.

[17] E. F. Fama and K. R. French, "The capital asset pricing model: theory and evidence," Journal of Economic Perspectives, vol. 18, no. 3, pp. 25-46, 2004.

[18] R. E. Lucas Jr., "Asset prices in an exchange economy," Econometrica, vol. 46, no. 6, pp. 1429-1445, 1978.

[19] S. J. Grossman and G. Laroque, "Asset pricing and optimal portfolio choice in the presence of illiquid durable consumption goods," Econometrica, vol. 58, no. 1, pp. 25-51, 1990.

[20] M. Flavin and S. Nakagawa, "A model of housing in the presence of adjustment costs: a structural interpretation of habit persistence," American Economic Review, vol. 98, no. 1, pp. 474-495, 2008.
[21] M. Piazzesi, M. Schneider, and S. Tuzel, "Housing, consumption and asset pricing," Journal of Financial Economics, vol. 83, no. 3, pp. 531-569, 2007.

[22] K. Case, J. Cotter, and S. Gabriel, "Housing risk and return: evidence from a housing asset-pricing model," The Journal of Portfolio Management, vol. 37, no. 5, pp. 89-109, 2011.

[23] R. W. Banz, "The relationship between return and market value of common stocks," Journal of Financial Economics, vol. 9, no. 1, pp. 3-18, 1981.

[24] Ò. Jordà, K. Knoll, D. Kuvshinov, M. Schularick, and A. M. Taylor, "The rate of return on everything, 1870-2015," The Quarterly Journal of Economics, vol. 134, pp. 1225-1298, 2019.

[25] A. Anari and J. Kolari, "House prices and inflation," Real Estate Economics, vol. 30, no. 1, pp. 67-84, 2002.

[26] G. K. Turnbull, J. L. Glascock, and C. F. Sirmans, "Uncertain income and housing price and location choice," Journal of Regional Science, vol. 31, no. 4, pp. 417-433, 1991.

[27] R. C. Merton, "Lifetime portfolio selection under uncertainty: the continuous-time case," The Review of Economics and Statistics, vol. 51, no. 3, pp. 247-257, 1969.

[28] J. Y. Campbell, "A variance decomposition for stock returns," The Economic Journal, vol. 101, no. 405, pp. 157-179, 1991.

[29] A. Black, P. Fraser, and M. Hoesli, "House prices, fundamentals and bubbles," Journal of Business Finance \& Accounting, vol. 33, no. 9-10, pp. 1535-1555, 2006.

[30] J. Fairchild, J. Ma, and S. Wu, "Understanding housing market volatility," Journal of Money, Credit and Banking, vol. 47, no. 7, pp. 1309-1337, 2015.

[31] A. Levitin, D. Lin, and S. Wachter, "Mortgage risk premiums during the housing bubble," Journal of Real Estate Finance and Economics, vol. 23, pp. 1-48, 2018.

[32] G. Meen, A. Mihailov, and Y. Wang, Endogenous uk Housing Cycles and the Risk Premium: Understanding the Next Housing Crisis, Economics \& Management Discussion Papers EmDp2016-02, Henley Business School, Reading University, Henley-on-Thames, UK, 2016, https://ideas.repec.org/p/rdg/ emxxdp/em-dp2016-02.html.

[33] C. Liu, Y. Zheng, Q. Zhao, and C. Wang, "Financial stability and real estate price fluctuation in China," Physica A: Statistical Mechanics and Its Applications, vol. 540, p. 122980, 2020.

[34] J. F. Cocco, "Portfolio choice in the presence of housing," Review of Financial Studies, vol. 18, no. 2, pp. 535-567, 2005.

[35] V. Acharya and L. Pedersen, "Asset pricing with liquidity risk," Journal of Financial Economics, vol. 77, no. 2, pp. 375-410, 2005.

[36] C.-C. Chang, W.-Y. Huang, and S.-D. Shyu, "Pricing mortgage insurance with asymmetric jump risk and default risk: evidence in the U.S. Housing market," The Journal of Real Estate Finance and Economics, vol. 45, no. 4, pp. 846-868, 2012.

[37] M.-C. Chuang, W.-R. Yang, M.-C. Chen, and S.-K. Lin, "Pricing mortgage insurance contracts under housing price cycles with jump risk: evidence from the U.K. housing market," The European Journal of Finance, vol. 24, no. 11, pp. 909-943, 2018.

[38] K. E. Dynan, "How prudent are consumers?" Journal of Political Economy, vol. 101, no. 6, pp. 1104-1113, 1993.

[39] E. C. M. Hui, J. Chen, and K. K. K. Chan, "House Hedging Model - which income group is more affected by risk?" Physica A: Statistical Mechanics and Its Applications, vol. 529, p. 121537, 2019. 